\title{
OPTIMIZATION OF PARAMETERS OF A PLANETARY GEARBOX USING THE TAGUCHI-GREY RELATIONAL ANALYSIS
}

Optimization of parameters of central gears of a planetary gearbox was performed in this study. Since the optimization of multi-performance characteristics is more complex compared to optimization of a single-performance characteristics, the Taguchi-Grey analysis was used. That approach combines the Taguchi orthogonal array L27 with the Grey relational analysis to determine the influence of the material, module and gear width on the safety coefficient of the planetary gearbox. A Grey relational grade obtained from the Grey relational analysis is used as the performance characteristics in the Taguchi method and Analysis of variance (ANOVA). The optimal combination of parameters for the safety coefficient values was obtained, when the value of the Grey relational grade is 1. Based on the ANOVA analysis, it was established that the most influential parameter is the module, then the gear width and the least influential one is the material.

Keywords: Taguchi method, Grey relational analysis, ANOVA, optimization, planetary gearbox

\section{Introduction}

The planetary gear transmissions are widely used in industrial applications for motion and power transmission such as automotive, aerospace, robotics, machinery etc., because of their significant advantages including the compact structure, selfcentering capability, high power density, high transmission ratios, high degree of efficiency, durability in operation, low level of noise and vibrations.

Design of planetary gear transmissions depends on a large number of parameters, some of those are: material, module, addendum, profile shift, tooth thickness, dedendum, cutter tip radius, pressure angle, gear width etc. The analysis and optimization of one simple planetary gearbox marked as $A_{h a}^{b}$ was performed in this paper. The letters in the mark $A_{h a}^{b}$ mean: A-the single-sided satellite, b-the fixed gear (internal toothed gear), a-the central gear (driving gear), h-the satellite carrier (connected to the output shaft) [1], [2]. Planetary gearbox of this type is shown in Figure 1, and next to already mentioned gears and satellite carrier, it consists of three satellites ( $\mathrm{g}$ ), as well.

The optimization of a simple planetary gear train was performed by authors of [3], they were observing the results obtained by changing the number of gear teeth, module, number of satellites and gear width. For development of a mathematical model for multi objective optimization they used the Puerto and ELECTRE methods and noticed that the correlations between used methods are obvious. This kind of approach shows that the other planetary gear transmission types can be subjects of the multi objective optimization. The multi objective approach in optimization is much faster with the use of the Taguchi-Grey method. For optimization of the plastic gear production authors in [4] applied the hybrid integration of Taguchi parametric design, the Grey relational analysis and the principal component analysis. For demonstration of efficiency and validity of the proposed hybrid optimization methods, in controlling all the influential injection molding processing parameters during the plastic gear manufacturing, a plastic gear was used. The optimal combination of different process parameters is determined in order to minimize the shrinkage behavior in tooth thickness, addendum circle and dedendum circle of the molded gear. They concluded that the proposed optimization method can produce a plastic-molded gear with minimum shrinkage behavior of $1.8 \%$ in tooth thickness, $1.53 \%$ in addendum circle and $2.42 \%$ in dedendum circle and it should be noted that these values are less than the values in the main experiment. Therefore, defects related to shrinkage that lead to severe failure in plastic gears can be effectively minimized while satisfying the demand of the global plastic gear industry [5].

The Taguchi method is a well-known optimization method, which is used in a variety of applications [5], [6]. Application of this method ensures savings in labor and time costs, with simultaneously examining several parameters in several experimental conditions, providing the quantitative information, [7], [8]. Limitation of the Taguchi method is that it can only be applied to solve individual objective problems and cannot be used for problems with multiple objectives optimization, especially when there are different performance characteristics needed. However, this problem has been overcome and the optimization of multiple objectives can be performed by combining the Taguchi method and the Grey relational analysis to optimize the multiple characteristics [9]. Combination of the Taguchi method and the Grey relational analysis was used for optimization of the EDM process (Electrical Discharge Machining) in [10]. Parameters of machining (workpiece polarity, pulse on time, duty factor, open discharge voltage, discharge current and dielectric fluid) were optimized considering the multiple performance characteristics including material removal rate, surface roughness and electrode wear ratio. The Taguchi-Grey method was really

\footnotetext{
* ${ }^{1}$ Slavica Miladinovic, ${ }^{1}$ Sandra Velickovic, ${ }^{1}$ Blaza Stojanovic, ${ }^{2}$ Ruzica Nikolic

${ }^{1}$ Faculty of Engineering, University of Kragujevac, Serbia

${ }^{2}$ Research Center, University of Zilina, Slovakia

E-mail: ruzicarnikolic@yahoo.com
} 


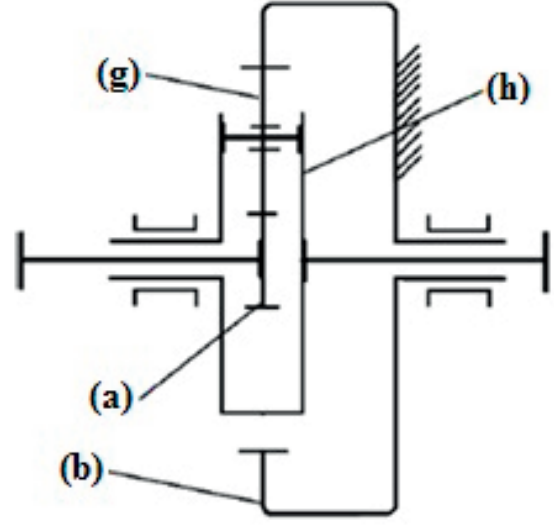

(a)

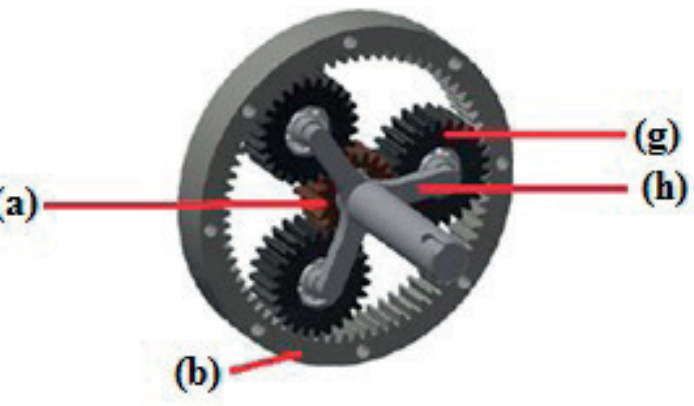

(b)

Figure 1 Planetary gearbox of type $A_{h a}^{b}:$ (a) Schematic presentation and (b) the 3D appearance of the planetary gearbox

Table 1 Control factors with their levels

\begin{tabular}{ccccc}
\hline Control factors & Units & Level I & Level II & Level III \\
\hline Material (A) & $/$ & $16 \mathrm{MnCr} 5$ & $28 \mathrm{Cr} 4$ & 2.75 \\
Module (B) & {$[\mathrm{mm}]$} & 2.50 & 33 & 3.00 \\
Gear width (C) & {$[\mathrm{mm}]$} & 30 & 36 \\
\hline
\end{tabular}

needed for optimization of the EDM process because material removal rate is the higher-the-better performance characteristics and the surface roughness and electrode wear ratio are the lowerthe-better performance characteristics - improvement of one performance characteristics may require a degradation of the other performance characteristics. This is the main reason that optimization of the multiple performance characteristics is much more complicated than optimization of a single performance characteristics. The Taguchi-Grey method has proven in this case that the machining performance in the EDM process can be effectively improved. Another successful application of the Taguchi-Grey method was in the color filter manufacturing [11] for improving the yield of Chrome $(\mathrm{Cr})$ thin-film sputtering process of the black matrix (BM) and to find the robust parameters of the process with multiple quality characteristics, as well. For the experiment, the Taguchi L9 orthogonal array was chosen and the two quality characteristics and four control factors with three levels were considered. The correlation between the quality characteristics was considered and, for elimination of the multiple colinearity, the principal component analysis was applied. The entropy measurement method was applied for obtaining the weights of the quality characteristics. After confirmation of the experiment, it was concluded that manufacturing with optimal parameters, obtained by the Taguchi-Grey method, can reduce the opportunities of the repair and rework of the $\mathrm{Cr}$ thin-film and raise the yield.

The Taguchi-Grey method can be applied in various aspects of industry, from optimization of processes to optimization of a single machine or part of a machine.

In this paper, the Taguchi-Grey method was applied for optimization of the safety coefficient for the surface durability of the entire planetary gearbox. The safety coefficients for the surface durability of the first gear pair a-g $\left(\mathrm{S}_{\mathrm{H} 1-2}\right)$ and the second gear pair $\mathrm{g}-\mathrm{b}\left(\mathrm{S}_{\mathrm{H} 2-3}\right)$ were considered. Influence of parameters, such as the material, module and the gear width, was analyzed to obtain the largest value of the safety coefficient. The planetary gearbox considered in this paper was chosen since it is the simplest one; the Taguchi-Grey method can be successfully applied for other types of planetary gearboxes that are more complex than the considered gearbox, with taking into account some restrictions.

\section{Experiments' design}

The Taguchi method is one of the most useful techniques for a single-response optimization studies used for a number of engineering problems. When there is a multi-response optimization of processes, the use of Taguchi methodis is not reliable and it should be combined with some other method, e.g. the Grey relational analysis.

The experiments were designed using the Taguchi design of experimental methods, which are based on an orthogonal array of experiments, resulting in optimal setting of the process control parameters. The orthogonal array provides a set of balanced experiments with less number of experimental runs, in order to evaluate the optimal parameters. For computing of the Taguchi data and data analysis the MiniTab 16 was used.

In this paper, the orthogonal array L27 was chosen, which provides the least combination of parameters in a matrix. Those parameters were different and in this way the direct effect on the observed output was achieved. The chosen input parameters of the planetary gearbox are material, module and the gear width and they are all parameters of the third level. Levels of chosen parameters and their marks are listed in Table 1.

The Taguchi method employs the signal to noise $(\mathrm{S} / \mathrm{N})$ ratio, to measure the performance of the process response. The $(\mathrm{S} / \mathrm{N})$ ratio, being the ratio of the mean to standard deviation, can effectively consider the variation encountered in a set of 
Table 2 Experimental design using the L27 orthogonal array

\begin{tabular}{|c|c|c|c|c|c|c|c|c|}
\hline \multirow{2}{*}{$\begin{array}{l}\text { Exp. } \\
\text { No }\end{array}$} & \multirow[b]{2}{*}{ A } & \multirow[b]{2}{*}{$\mathrm{B}$} & \multirow[b]{2}{*}{$\mathrm{C}$} & \multicolumn{2}{|c|}{ Experimental results } & \multirow{2}{*}{$\begin{array}{l}\text { The Grey } \\
\text { grade }\end{array}$} & \multirow{2}{*}{$\begin{array}{l}\mathrm{S} / \mathrm{N} \text { for the } \\
\text { Grey grade }\end{array}$} & \multirow[b]{2}{*}{ Rank } \\
\hline & & & & $\mathrm{S}_{\mathrm{H} 1-2}$ & $\mathrm{~S}_{\mathrm{H} 2-3}$ & & & \\
\hline 1 & $16 \mathrm{MnCr} 5$ & 2.50 & 30 & 1.31 & 2.36 & 0.36716 & -8.70297 & 25 \\
\hline 2 & $16 \mathrm{MnCr} 5$ & 2.50 & 33 & 1.37 & 2.47 & 0.40345 & -7.88425 & 21 \\
\hline 3 & $16 \mathrm{MnCr} 5$ & 2.50 & 36 & 1.42 & 2.57 & 0.44152 & -7.10098 & 19 \\
\hline 4 & $16 \mathrm{MnCr} 5$ & 2.75 & 30 & 1.44 & 2.59 & 0.45408 & -6.85741 & 17 \\
\hline 5 & $16 \mathrm{MnCr} 5$ & 2.75 & 33 & 1.51 & 2.71 & 0.51924 & -5.69263 & 12 \\
\hline 6 & $16 \mathrm{MnCr} 5$ & 2.75 & 36 & 1.57 & 2.82 & 0.59492 & -4.51088 & 8 \\
\hline 7 & $16 \mathrm{MnCr} 5$ & 3.00 & 30 & 1.58 & 2.82 & 0.60218 & -4.40554 & 7 \\
\hline 8 & $16 \mathrm{MnCr} 5$ & 3.00 & 33 & 1.64 & 2.95 & 0.71780 & -2.87995 & 4 \\
\hline 9 & $16 \mathrm{MnCr} 5$ & 3.00 & 36 & 1.71 & 3.07 & 0.89541 & -0.95958 & 2 \\
\hline 10 & $28 \mathrm{Cr} 4$ & 2.50 & 30 & 1.33 & 2.39 & 0.37743 & -8.46331 & 24 \\
\hline 11 & $28 \mathrm{Cr} 4$ & 2.50 & 33 & 1.39 & 2.5 & 0.41588 & -7.62063 & 20 \\
\hline 12 & $28 \mathrm{Cr} 4$ & 2.50 & 36 & 1.45 & 2.61 & 0.46306 & -6.68725 & 16 \\
\hline 13 & $28 \mathrm{Cr} 4$ & 2.75 & 30 & 1.46 & 2.63 & 0.47241 & -6.51365 & 15 \\
\hline 14 & $28 \mathrm{Cr} 4$ & 2.75 & 33 & 1.53 & 2.75 & 0.54334 & -5.29850 & 11 \\
\hline 15 & $28 \mathrm{Cr} 4$ & 2.75 & 36 & 1.59 & 2.87 & 0.63134 & -3.99473 & 6 \\
\hline 16 & $28 \mathrm{Cr} 4$ & 3.00 & 30 & 1.51 & 2.86 & 0.57470 & -4.81114 & 10 \\
\hline 17 & $28 \mathrm{Cr} 4$ & 3.00 & 33 & 1.67 & 2.99 & 0.77659 & -2.19617 & 3 \\
\hline 18 & $28 \mathrm{Cr} 4$ & 3.00 & 36 & 1.74 & 3.12 & 1.00000 & 0.00000 & 1 \\
\hline 19 & C15E & 2.50 & 30 & 1.24 & 2.24 & 0.33333 & -9.54243 & 27 \\
\hline 20 & $\mathrm{C} 15 \mathrm{E}$ & 2.50 & 33 & 1.3 & 2.34 & 0.36149 & -8.83814 & 26 \\
\hline 21 & C15E & 2.50 & 36 & 1.35 & 2.44 & 0.39174 & -8.14002 & 23 \\
\hline 22 & $\mathrm{C} 15 \mathrm{E}$ & 2.75 & 30 & 1.37 & 2.46 & 0.40161 & -7.92385 & 22 \\
\hline 23 & C15E & 2.75 & 33 & 1.43 & 2.57 & 0.44544 & -7.02428 & 18 \\
\hline 24 & $\mathrm{C} 15 \mathrm{E}$ & 2.75 & 36 & 1.49 & 2.68 & 0.50000 & -6.02060 & 13 \\
\hline 25 & $\mathrm{C} 15 \mathrm{E}$ & 3.00 & 30 & 1.49 & 2.68 & 0.50000 & -6.02060 & 13 \\
\hline 26 & $\mathrm{C} 15 \mathrm{E}$ & 3.00 & 33 & 1.56 & 2.8 & 0.58017 & -4.72887 & 9 \\
\hline 27 & $\mathrm{C} 15 \mathrm{E}$ & 3.00 & 36 & 1.62 & 2.92 & 0.68159 & -3.32956 & 5 \\
\hline
\end{tabular}

experimental runs. The $(\mathrm{S} / \mathrm{N})$ ratios, which are log functions of a desired output, serve as the objective functions for optimization, help in the data analysis and prediction of the optimum results. There are three types of the $(\mathrm{S} / \mathrm{N})$ ratio analyses that are generally applicable: the-higher-the-better, the-nominal-the-better and thelower-the-better [7].

In this study, the higher-the-better quality characteristics has been used for calculating the $(\mathrm{S} / \mathrm{N})$ ratio for the Grey grade of the responses. The $(\mathrm{S} / \mathrm{N})$ ratio can be calculated using the following equation:

$$
S / N=-10 \log \left(\frac{1}{n} \sum_{i=1}^{n} \frac{1}{y_{i}^{2}}\right)
$$

where $y_{i}$ is the performance value of the $i$-th experiment and $n$ is the number of experiments.

Results of all 27 experiments and the corresponding $(\mathrm{S} / \mathrm{N})$ ratios for the Grey grade are shown in Table 2.

\section{Optimization using the Grey relational analysis}

When there are multiple outputs, a combination of the Taguchi method and the Grey relational analysis is usually used for optimization. In this case, the Grey relational analysis is used to generate a single response for the two performance characteristics. Like in the Taguchi design, in the Grey relational analysis, there are also three quality characteristics: the-higher-thebetter, the-nominal-the-better and the-lower-the-better.

In Table 2 are given experimental results, the Grey grade, the signal-to-noise ratio $(\mathrm{S} / \mathrm{N})$ for the Grey grade and results are ranked. Basically, the larger the Grey relational grade is, the closer the product quality will be to the ideal value.

In this paper, for the desired higher values of the safety coefficients of surface durability of a planetary gearbox at the output (the-higher-the-better quality characteristics), normalizing in the range of $0-1$ was done according to the following equation [12]:

$$
x_{i}(k)=\frac{y_{i}(k)-\min y_{i}(k)}{\max y_{i}(k)-\min y_{i}(k)}
$$


Table 3 Analysis of variance for the $(S / N)$ ratios for the Grey grade

\begin{tabular}{|c|c|c|c|c|c|c|c|}
\hline Source & $\mathrm{DF}$ & Seq SS & Adj SS & Adj MS & $\mathrm{F}$ & $\mathrm{P}$ & $\operatorname{Pr} \%$ \\
\hline A & 2 & 15.748 & 15.748 & 7.8738 & 118.89 & 0.000 & 10.09 \\
\hline B & 2 & 106.377 & 106.377 & 53.1883 & 803.11 & 0.000 & 68.17 \\
\hline $\mathrm{C}$ & 2 & 28.120 & 28.120 & 14.0602 & 212.30 & 0.000 & 18.02 \\
\hline$A * B$ & 4 & 1.140 & 1.140 & 0.2849 & 4.30 & 0.038 & 0.73 \\
\hline$A^{*} \mathrm{C}$ & 4 & 0.820 & 0.820 & 0.2049 & 3.09 & 0.081 & 0.53 \\
\hline $\mathrm{B}^{*} \mathrm{C}$ & 4 & 3.304 & 3.304 & 0.8260 & 12.47 & 0.002 & 2.12 \\
\hline Residual Error & 8 & 0.530 & 0.530 & 0.0662 & & & 0.34 \\
\hline Total & 26 & 156.038 & & & & & 100.00 \\
\hline
\end{tabular}

DF - degree of freedom, Seq SS - Sequential sum of squares, Adj SS - Adjusted sum of squares, Adj MS - Adjusted mean square, F-value, Pr-percentage of contribution

Table 4 Response for the Grey grade

\begin{tabular}{ccccc}
\hline Level & A & B & C \\
\hline 1 & -5.444 & -8.109 & -7.027 \\
2 & -5.065 & -5.982 & -5.796 \\
3 & -6.841 & -3.259 & -4.527 & 2.500 \\
Delta & 1.776 & 4.850 & 2 \\
Rank & 3 & 1 & 2 \\
\hline
\end{tabular}

where: $k$ is the number of factors, in range $1-3, i$ is the experiment number, in range 1-27, $\max y_{i}(k)$ is the highest experimental value for the $k$-th output and $\min y_{i}(k)$ is the lowest experimental value for the $k$-th output [13].

For the-smaller-the-better quality characteristics and thenominal-the-better quality characteristics Equation (3) and Equation (4) are used, respectively [13]:

$x_{i}(k)=\frac{y_{i}(k)-\min y_{i}(k)}{\max y_{i}(k)-\min y_{i}(k)}$

$x_{i}(k)=\frac{\left|y_{i}(k)-O B\right|}{\max \left\{\max y_{i}(k)-O B, O B-\min y_{i}(k)\right\}}$

The absolute difference value is calculated according to expression [13]:

$\Delta_{0 i}=\left\|x_{0}(k)-x_{i}(k)\right\|$

where: $x_{0}(k)$ is the referential normalized value $\left(x_{0}(x)=1\right)$.

The Grey relational coefficient is calculated according to [9], [12]:

$\xi_{i}(k)=\frac{\Delta_{\min }+\zeta \Delta_{\max }}{\Delta_{0 i}(k)+\zeta \Delta_{\max }}$

where: $\Delta_{\min }$ and $\Delta_{\max }$ are the lowest and the highest values of absolute difference, respectively, $\zeta$ is the distinguishing coefficient in the interval $0 \leq \zeta \leq 1$; if the weighting of output is equal, then $\zeta=0.5$ [5], [12].

Then, the Grey relational grade $\left(\gamma_{i}\right)$ can be calculated according to:

$\gamma_{i}=\frac{1}{n} \sum_{k=1}^{n} \xi_{i}(k)$

where $n$ is the number of outputs; $\gamma_{i}$ has to be as high as possible.
The experimental data are analyzed by using the Taguchi signal-to-noise ratio to measure the performance of the process response. The $(\mathrm{S} / \mathrm{N})$ ratio is the objective function for optimization and with the use of a logarithmic function it helps in data analysis and in prediction of the optimal results. In this paper, the-higher-the-better quality characteristics was used for calculating the $(S / N)$ ratios of the responses [5], [6], [7]. In this way, the multiple response problems are converted into a single response problem.

\section{Analysis of variance}

Analysis of variance (ANOVA) is a statistical model used for finding the most influential parameter that contributes towards the outputs and how the variations in inputs affect the outputs. This method is easy to understand and use when the number of parameters is small.

The effect of material, module and gear width on the safety coefficients for the surface durability of a planetary gearbox was analyzed with the $95 \%$ confidence level and 5\% significance level [13]. The probability values show the level of significance of each factor, the parameter is highly statistically significant if the corresponding $\mathrm{P}$ value is less than 0.05 . Table 3 shows the results of the ANOVA for multi-performance characteristics.

According to the ANOVA, the most significant control parameter is the module with contribution of about $68.17 \%$, followed by the gear width with $18.02 \%$ and material with $10.09 \%$. Interactions of observed parameters are insignificant because their effects on the safety coefficients were negligible. Analysis of parameters' influences was obtained from the response tables of the mean $(\mathrm{S} / \mathrm{N})$ ratio and the results are listed in Table 4. The larger values of the $(\mathrm{S} / \mathrm{N})$ ratio correspond to the better quality, thus the optimal combination of design parameters was obtained as $\mathrm{A} 2 \mathrm{~B} 3 \mathrm{C} 3$, which is also shown in Figure2. 


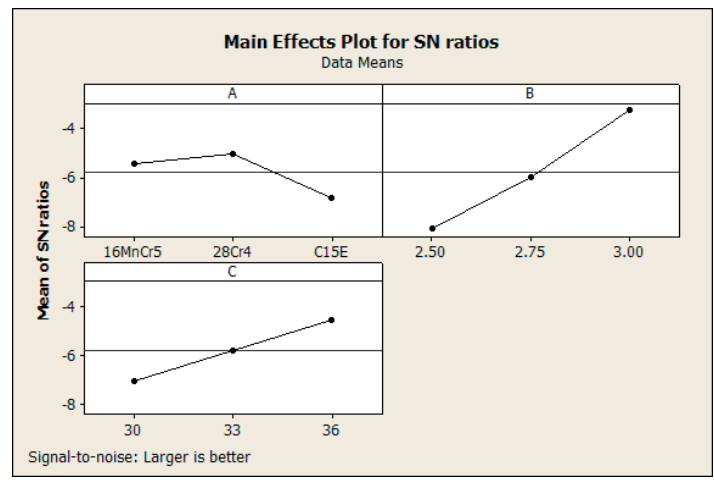

a)

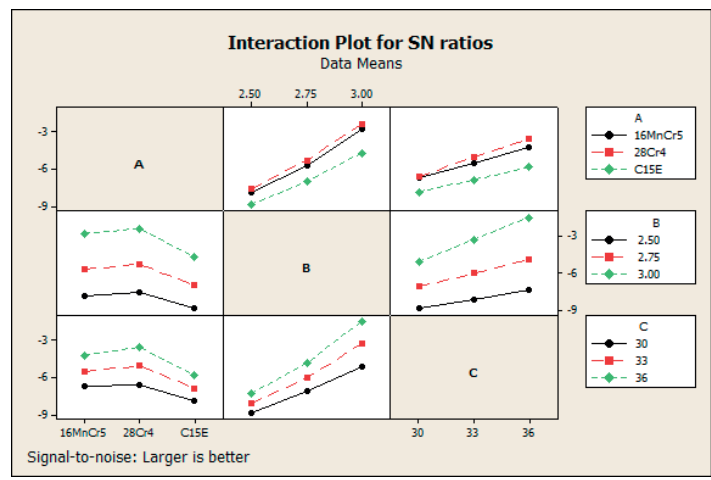

b)

Figure 2 Plots of the $(S / N)$ ratio for the safety coefficients for the durability of a planetary gearbox: a) main effects plot; b) interaction plot

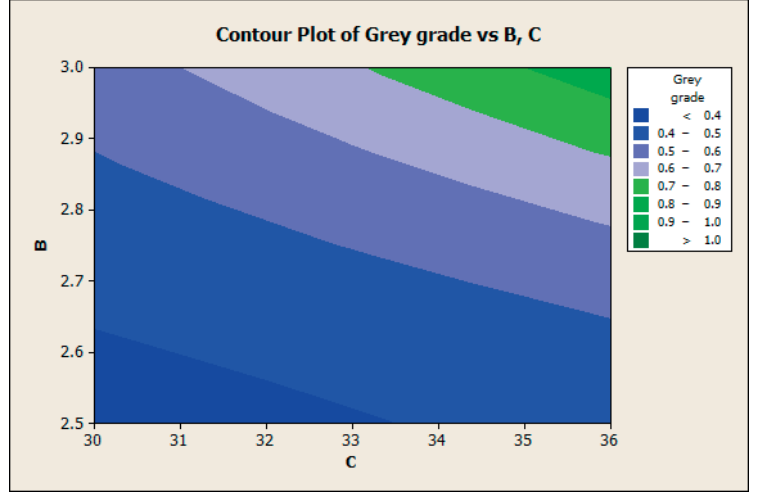

a)

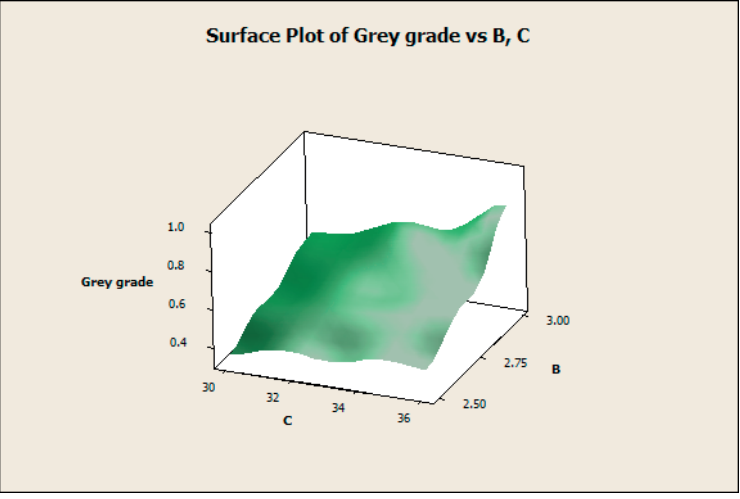

b)

Figure 3 Response plots of combined effect of module and gear width on the surface durability of a planetary gearbox: a) contour plot; b) surface plot

In Figure 3 are presented the contour plot (Figure 3a) and the surface plot (Figure $3 b$ ) of combined effect of module and the gear width on the Grey grade for the safety coefficients of surface durability of a planetary gearbox.

Based on the carried out analysis and on the plots shown in Figure 3, it can be concluded that the highest surface durability of a planetary gearbox is achieved for the highest values of the module and the gear width.

\section{Conclusions}

In this study, the Taguchi's orthogonal array with the Grey relational analysis was used to optimize the multiple performance characteristics and the following conclusions were drawn:

- According to results of the ANOVA analysis, the main contributing factors, affecting the safety coefficients for the surface durability of a planetary gearbox, were material, module and the gear width, with contributions of $10.09 \%$, $68.17 \%$ and $18.02 \%$, respectively. Interaction of parameters $\mathrm{B}^{*} \mathrm{C}$ (module*gear width) has influence of $2.12 \%$, interactions of other parameters had negligible influences;

- The optimal combination of parameters, according to the Taguchi-Grey analysis is $\mathrm{A} 2 \mathrm{~B} 3 \mathrm{C} 3$, which means that the highest values of the safety coefficients for the surface durability of a planetary gearbox are for material $28 \mathrm{Cr} 4$, module of $3 \mathrm{~mm}$ and the gear width of $36 \mathrm{~mm}$. The Grey grade for this optimal combination of parameters is 1 and the $(\mathrm{S} / \mathrm{N})$ ratio is 0 ;

- Based on results from the applied methods, one can conclude that the Taguchi-Grey method can be applied for optimization of the safety coefficients for the surface durability of a planetary gearbox.

Results of this research suggest that the complex optimization of the multi-response problems with the Taguchi method can be easily simplified by adding the Grey relational analysis. Joined strength of these two methods has given more precise safety coefficients for the surface durability of a planetary gearbox.

Note: Shorter version of this research was presented at "SEMDOK 2018" Conference, reference [14].

\section{Acknowledgement}

This research was financially supported by European regional development fund and Slovak state budget by the project "Research Centre of the University of Zilina" and by the Ministry of Education, Science and Technological Development of Republic of Serbia through grant TR 35021. 


\section{References}

[1] MILADINOVIC, S., VELICKOVIC, S., NOVAKOVIC, M.: Application of Taguchi method for the Selection of Optimal Parameters of Planetary Driving Gear. Applied Engineering Letters, 1(4), 98-104, 2016.

[2] TANASIJEVIC, S., VULIC, A.: Mechanical Transmitters - Planetary Transmitters and Variators (in Serbian). Faculty of Mechanical Engineering, Kragujevac, 2006.

[3] STEFANOVIC-MARINOVIC, J., PETKOVIC, M., STANIMIROVIC, I.: Application of the ELECTRE Method to Planetary Gear Train Optimization. Journal of Mechanical Science and Technology, 29(2), 647-654, 2015. https://doi.org/10.1007/s12206015-0124-z

[4] MEHAT, N. M., KAMARUdDIN, S., OTHMAN, A. R.: Hybrid Integration of Taguchi Parametric Design Grey Relational Analysis and Principal Component Analysis Optimization for Plastic Gear Production.Chinese Journal of Engineering, 1-11, 2014. http://dx.doi.org/10.1155/2014/351206

[5] MiladinOVIC, S., RAdosAVlJeVIC, S., VelickOVIC, S., ATYAT, R., SKUliC, A., SLJIVIC, V.: Optimization of Efficiency of Worm Gear Reducer by Using Taguchi-Grey Method. Applied Engineering Letters, 2(2), 69-75, 2017.

[6] RAMDUMAR, R., KEN, M.: Minimization of Shrinkage in Injection Molding Process of Acetal Polymer Gear Using Taguchi DOE Optimization and ANOVA Method. International Journal of Mechanical and Industrial Technology, 4(2),72-79, 2017.

[7] STOJANOVIC, B., BLAGOJEVIC, J., BABIC, M., VELICKOVIC, S., MILADINOVIC, S.: Optimization of Hybrid Aluminum Composites Wear Using Taguchi Method and Artificial Neural Network. Industrial Lubrication and Tribology, 69(6),1005-1015, 2017. https://doi.org/10.1108/ILT-02-2017-0043

[8] MILADINOVIC, S., VELICKOVIC, S.: Optimization and Prediction of Safety Coefficient for Surface Durability of Planetary Gearbox using Taguchi Design and Artificial Neural Network. Proceedings of the $3^{\text {rd }}$ International Scientific Conference COMETa, Bosnia and Herzegovina, 139-146, 2016.

[9] YUNUS, M., ALSOUFI, M. S., MUNSHI, S. M.: Taguchi-Grey Relation Analysis for Assessing the Optimal Set of Control Factors of Thermal Barrier Coatings for High-Temperature Applications. Mechanics of Advanced Materials and Modern Processes, 2(4), 1-8, 2016. https://doi.org/10.1186/s40759-016-0011-z

[10] LIN, J. L.,LIN, C. L.: The Use of the Orthogonal Array with Grey Relational Analysis to Optimize the Electrical Discharge Machining Process with Multiple Performance Characteristics. International Journal of Machine Tools and Manufacture,42, 237-244, 2002.

[11] CHIANG, Y.M. , Hsieh, H. H.: The Use of the Taguchi Method with Grey Relational Analysis to Optimize the Thin-Film Sputtering Process with Multiple Quality Characteristic in Color Filter Manufacturing, Computers and Industrial Engineering, 56(2), 648-661, 2008. https://doi.org/10.1016/j.cie.2007.12.020

[12] SUDEEPANA, J., KUMARB, K., BARMANC, T. K., SAHOOC, P.: Study of Tribological Behavior of ABS/CaCO 3 Composite Using Grey Relational Analysis. Procedia Materials Science, 6, 682-691, 2014. https://doi.org/10.1016/j.mspro.2014.07.084

[13] STOJANOVIC B., BABIC M., IVANOVIC L.: Taguchi Optimization of Tribological Properties of Al/SiC/Graphite Composite. Journal of the Balkan Tribological Association, 22(3), 2592-2605, 2016.

[14] MiladinOVIC, S., VeliCKOVIC, S., STOJANOVIC, B., NIKOLIC, R.: The Taguchi-Grey Relational Analysis for Optimization of the Safety Coefficient for the Surface Durability of a Planetary Gearbox. Proceedings of the $23^{\text {rd }}$ International Seminar of Ph.D. Students SEMDOK 2018, Slovakia, 118-123, 2018. 